\title{
Heat treatment following surface silanization in rebonded tribochemical silica-coated ceramic brackets: shear bond strength analysis
}

\author{
Emilia Adriane SILVA, Flávia Zardo TRINDADE², Hélcio Nagib José Feres RESKALLA', José Renato Cavalcanti de \\ QUEIROZ $^{3}$
}

\footnotetext{
1- DDS, MSc, Department of Restorative Dentistry, Federal University of Juiz de Fora, Juiz de Fora, MG, Brazil.

2- DDS, MSc, PhD, Department of Implantology, School of Dentistry, University of Santo Amaro, SP, Brazil.

3- DDS, MSc, PhD, Department of Biotechnology, Potiguar University, Natal, RN, Brazil.
}

Corresponding address: José Renato Cavalcanti de Queiroz - Av. Gov. Juvenal Lamartine, 326 (903-II) - Tirol - Natal - RN Brazil - 59.020-280 - Phone: 558499870445 - e-mail: joserenatocq@hotmail.com

Submitted: January 8, 2013 - Modification: March 14, 2013 - Accepted: June 4, 2013

\section{ABSTRACT}

\begin{abstract}
bjective: This study aimed to evaluate the effects of heat treatment on the tribochemical silica coating and silane surface conditioning and the bond strength of rebonded alumina monocrystalline brackets. Material and Methods: Sixty alumina monocrystalline brackets were randomly divided according to adhesive base surface treatments $(n=20)$ : $G c$, no treatment (control); Gt, tribochemical silica coating + silane application; Gh, as per Gt + post-heat treatment (air flux at $100^{\circ} \mathrm{C}$ for $60 \mathrm{~s}$ ). Brackets were bonded to the enamel premolars surface with a light-polymerized resin and stored in distilled water at $37^{\circ} \mathrm{C}$ for 100 days. Additionally, half the specimens of each group were thermocycled $(6,000$ cycles between $5-55^{\circ} \mathrm{C}$ ) (TC). The specimens were submitted to the shear bond strength (SBS) test using a universal testing machine $(1 \mathrm{~mm} / \mathrm{min})$. Failure mode was assessed using optical and scanning electron microscopy (SEM), together with the surface roughness (Ra) of the resin cement in the bracket using interference microscopy (IM). 2-way ANOVA and the Tukey test were used to compare the data $(p>0.05)$. Results: The strategies used to treat the bracket surface had an effect on the SBS results $(p=0.0)$, but thermocycling did not $(p=0.6974)$. Considering the SBS results (MPa), Gh-TC and Gc showed the highest

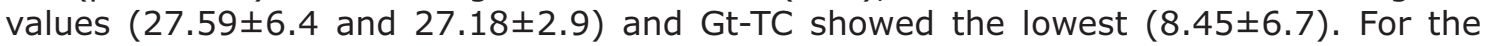
Ra parameter, ANOVA revealed that the aging method had an effect $(p=0.0157)$ but the surface treatments did not $(p=0.458)$. For the thermocycled and non-thermocycled groups, $\mathrm{Ra}(\mu \mathrm{m})$ was $0.69 \pm 0.16$ and $1.12 \pm 0.52$, respectively. The most frequent failure mode exhibited was mixed failure involving the enamel-resin-bracket interfaces. Conclusion: Regardless of the aging method, Gh promoted similar SBS results to Gc, suggesting that rebonded ceramic brackets are a more effective strategy.
\end{abstract}

Key words: Surface properties. Orthodontic brackets. Ceramics.

\section{INTRODUCTION}

In recent years, the interest in oral esthetics has increased, enhancing the demand for such considerations during orthodontic treatment and increasing the use of esthetic brackets, including translucent monocrystalline alumina brackets $(M A B)^{23}$. However, MAB has no chemical affinity with the resin composites that are used to bond the brackets to the enamel surface, consequently the "debonding" of these brackets is an important clinical complication for the orthodontist ${ }^{1}$. With this problem in mind, MAB manufacturers have mainly used mechanical retention to promote bonding between MAB and enamel ${ }^{23}$. Even so, some brackets can fall shortly after the initial bonding, while others have to be purposely repositioned midway through treatment ${ }^{27}$. 
The need to continue the orthodontic treatment requires the dentist to choose between two options: (1) replace the loose bracket with a new one; or (2) rebond the same bracket ${ }^{1,27}$. Reusing a debonded bracket is practical and presents lower cost. However, its performance could diminish if any additional surface treatment was applied to the base in brackets that use mechanical retention ${ }^{6}$. Thus, several chairside methods have been developed to treat the base surface of debonded brackets, such as removing the resin debris by electropolishing, Bunsen flame and sandblasting the surface ${ }^{10,22,26}$.

Two types of abrasive particles have been used to blast the base of the bracket: alumina particles and silica-modified alumina particles ${ }^{1}$. These surface modifications should improve resin-ceramic bonding by: a) removing any organic debris from the ceramic surface; b) improving the wetting kinetics of the bonding agents; and c) increasing roughness on flatted ceramic surfaces promoting micromechanical locking with the resinn $2,8,14,28$. In addition, the silica-modified alumina particles can deposit a layer of silica on the base of the surface of the ceramic bracket allowing reactions with the silane coupling agent. The silane agent applied to the surface reacts with surface hydroxyl groups, forming siloxane bond by condensation. Therefore, the silicatization process can improve bond strength results because it increases the number of hydroxyl groups ${ }^{15,16}$ on the silica-coated MAB surface, thus improving adhesion quality and compatibility with resin cements and promoting better results than ceramic brackets that are only sandblasted with alumina particles ${ }^{27}$.

However, the silanization process is considered technique-sensitive and its instability can cause deterioration in adhesion, particularly when applied to a chemically stable surface, as presented by $\mathrm{MAB}^{18}$. Consequently, efforts to improve silane layer quality that reduce hydrolytic degradation and increase the lifespan of this adhesion interface have been proposed ${ }^{20}$. Studies have shown that silane drying conditions and post-heat treatment procedures reduce solvents and enhance the crosslinking reaction to the silane layer, improving bond performance at the interface ${ }^{13,19,20}$. An increase was observed in the extent of cross-linking from the outer layers of the silane towards the ceramic surface, with a corresponding increase in mechanical and hydrothermal stability ${ }^{19}$. It is likely that the heat applied to a silanized surface catalyzes the reaction between silica and the silane coupling agent. The energy provided affects the network density, reducing water diffusing through the network, while improving chemical stability at this bond interface ${ }^{4,12}$.

Previous research tested the effect of post-heat treatment of silane on adhesion between inorganic (ceramics systems, quartz fiber post) and organic materials (resin composite, resin cement) $4,7,9,12,17,25$; however, the influence of silica coating followed by silanization and heat treatment on the bond strength of monocrystalline alumina, as used in $M A B$, has not yet been investigated.

The aim of this study was to evaluate the associated influence of silica coating, a silane coupling agent and post-heat treatment on the bond strength of a MAB-resin-enamel system and its effect on adhesive stability. The hypothesis tested was that the post-heat treatment increases the bond strength between the enamel, resin and "rebonded" $M A B$, improving the bond performance for this interface following different aging procedures.

\section{MATERIAL AND METHODS}

Sixty healthy premolar teeth (intact enamel, without bleaching and no caries) extracted in the course of orthodontic treatments, with informed consent from each patient, were obtained and stored in distilled water at $5^{\circ} \mathrm{C}$ for up to 2 months. Sixty monocrystalline alumina premolar brackets (Pure ${ }^{\circledR}$, OrthoTechnology, Tampa, FL, USA), using mechanical retention by zirconia pearls on the base, were randomly divided according to surface treatment strategy $(n=20)$ :

Gc, new brackets with no surface treatment (control group);

Gt, tribochemical silica coating with Cojet-Sand (3M ESPE, Seefeld, Germany), using a blasting device (Cojet-PrepTM, 3M ESPE, Seefeld, Germany). The distance between the base of the bracket and the nozzle was standardized at $10 \mathrm{~mm}$ and $90^{\circ}$ angle. A 2.8 bar pressure was exerted for $5 \mathrm{~s}$. Using a clean brush at room temperature $\left(20^{\circ} \mathrm{C}\right)$ and $50 \%$ relative humidity, one layer of Monobond-S (Ivoclar Vivadent AG, Schaan, Linchtenstein) was applied to the ceramic surface for $20 \mathrm{~s}$ and left on the ceramic surface for $60 \mathrm{~s}$ to allow the chemical reactions to occur. Then, the excess silane was removed by air spray, free of oil contamination, for $5 \mathrm{~s}$ at 2.8 bar;

$\mathrm{Gh}$, after the base surface of the brackets was prepared as described in Gs, post-heat treatment was applied to the silanized surface using a hot air dryer (Taiff 6000 W, São Paulo, SP, Brazil) at $100^{\circ} \mathrm{C}$ for $60 \mathrm{~s}$.

The bonding procedures were performed by the same operator. Prior to the bonding procedure, the adhesive area on the labial teeth surface was cleaned with prophylactic paste for $15 \mathrm{~s}$. An adhesive paper was positioned on the enamel to standardize the bonding interface area $\left(12.25 \mathrm{~mm}^{2}\right)$, avoiding adhesive flash on the enamel surface (Figure 1). The brackets were bonded with Transbond XT ( $3 \mathrm{M}$ Unitek, Monrovia, Ca, USA), in accordance with the manufacturer's instructions. Excess adhesive 
was gently removed and the brackets were lightcured (Optilight 600, Gnatus, São Paulo, SP, Brazil) for $10 \mathrm{~s}$. Then, teeth were vertically embedded in autopolymerized acrylic resin, sh that the limit of cementum-enamel on the buccal side was exposed $2 \mathrm{~mm}$ above the acrylic resin (Dencôr, Clássico, São Paulo, SP, Brazil).

The bonded teeth were stored under standard conditions in distilled water at $37^{\circ} \mathrm{C}$ for 100 days. In addition, half of the specimens for each group were thermocycled $(6,000$ cycles $)$ in water between $5 \pm 1^{\circ} \mathrm{C}$ and $55 \pm 1^{\circ} \mathrm{C}$ with a transfer time of $2 \mathrm{~s}$ and a dwell time of $30 \mathrm{~s}$ in each bath.

The shear bond strength test (knife-edge set-up) was performed with a universal testing machine DL1000 (EMIC, São José dos Pinhais, Brazil), in which the load was applied to the interface at $1 \mathrm{~mm} / \mathrm{min}$, using a $50 \mathrm{KgF}$ load-cell.

To determine the adhesive remnant index (ARI), the brackets were examined under a stereomicroscope at $35 x$ magnification (STEMI 2000-C, Zeiss, Jena, Germany) and a scanning electron microscope (SEM) (JEOL JSM 5800-LV, Tokyo, Japan) with values ranging up to $350 \mathrm{x}$ magnification in SE mode.

For the qualitative and quantitative topography analyses and roughness of the resin composite following the fracture of the samples, the regions corresponding to adhesive failure with the enamel

Table 1- The $p$ value by 2-way ANOVA determined for shear bond strength (SBS) and roughness parameters (Ra, RSm and Rc) for different factors (surface treatment, ST; Thermocycling, TC) $\left({ }^{*} p<0.05\right)$

\begin{tabular}{cccc}
\hline & ST & TC & ST + TC \\
\hline $\mathrm{p}$ for SBS & $0.0^{*}$ & 0.6974 & $0.0136^{*}$ \\
$\mathrm{p}$ for Ra & 0.4776 & $0.0037^{*}$ & 0.3676 \\
$\mathrm{p}$ for RSm & 0.3373 & 0.4116 & 0.6792 \\
$\mathrm{p}$ for Rc & 0.658 & $0.0018^{*}$ & 0.2013 \\
\hline
\end{tabular}

were evaluated in a digital optical profilometer (Wyko NT 1100, Veeco, Plainview, NY, USA) that was connected to a computer drive containing the software Vision 32 (Veeco). The roughness measurement parameters were performed at $20 x$ magnification on the central area of $301.3 \times 229.2$ $\mu \mathrm{m}$, with two measurements of five randomly selected brackets for each group. To observe the surface features, the rough surface profile was obtained using Gaussian filter to remove waviness and form. The roughness parameters evaluated were $(\mu \mathrm{m})$ :

Ra: Arithmetical mean of the absolute values of the surface departures from the mean plane within the sampling area. This is a general and commonly used parameter;

Rc: Mean height of the profile elements (peak and valley);

RSm: Mean width of the profile elements (peak and valley).

Statistical analysis for the SBS test was performed using 2-way ANOVA, considering the surface treatment and aging as the parameters tested. Multiple comparisons were performed by the Tukey adjustment test. A $p$ value of less than 0.05 was considered to be statistically significant for all tests.

\section{RESULTS}

Analysis of variance 2-way ANOVA for the shear bond strength (SBS) and roughness parameters are presented in Table 1. For RSm ( $\mu \mathrm{m})$, no statistically significant difference was determined by 2-way ANOVA. The mean RSm results $(\mu \mathrm{m})$ were $5.2 \mathrm{TC}$ groups and 5.39 for the non-TC groups. For Ra and $\mathrm{Rc}$, only the aging factor (TC) presented an effect on the results. The mean $\mathrm{Ra}$ and $\mathrm{Rc}$ results $(\mu \mathrm{m})$ were 0.31 and 0.87 for the TC groups and 0.39 and 1.10 for the non-TC groups. In the fracture analysis, the most frequent fracture mode was mixed failure. Mean bond strengths and standard deviations and

Table 2- Mean and standard deviation for shear bond strength (SBS), roughness parameters (Ra, RSm and Rc) and failure modes of the groups according to the adhesive remnant index (ARI) on the enamel surface: ARI 3, 100\% of composite; ARI 2, >50\% of composite; ARI 1, $<50 \%$ of composite; ARI $0,0 \%$ of composite. *Same superscript letters indicate no statistically significant differences for SBS. (Tukey test, $\alpha=0.05$ )

\begin{tabular}{lcccccccc}
\hline \multicolumn{1}{c}{ Groups } & SBS $(\mathrm{MPa})$ & \multicolumn{3}{c}{ Adhesive Remnant Index } & \multicolumn{3}{c}{ Roughness $(\boldsymbol{\mu m})$} \\
& & ARI 3 & ARI 2 & ARI 1 & ARI 0 & Ra & Rc & RSm \\
\hline Gc & $27.18^{\mathrm{a}} \pm 2.9$ & - & 1 & 9 & 0 & $0.43 \pm 0.1$ & $1.23 \pm 0.4$ & $5.5 \pm 0.8$ \\
Gt & $12.0^{\mathrm{bc}} \pm 6.1$ & 1 & 3 & 3 & 3 & $0.36 \pm 0.1$ & $1.04 \pm 0.2$ & $5.09 \pm 0.7$ \\
Gh & $19.16^{\mathrm{ab}} \pm 8.2$ & - & - & 8 & 2 & $0.37 \pm 0.1$ & $1.03 \pm 0.2$ & $5.58 \pm 0.5$ \\
Gc-TC & $24.33^{\mathrm{a}} \pm 5.1$ & - & - & 9 & 1 & $0.31 \pm 0.1$ & $0.82 \pm 0.1$ & $5.27 \pm 0.9$ \\
Gt-TC & $8.45^{\mathrm{c}} \pm 6.7$ & 3 & 1 & 6 & - & $0.32 \pm 0.1$ & $0.91 \pm 0.2$ & $5.13 \pm 0.4$ \\
Gh-TC & $27.59^{\mathrm{a}} \pm 6.4$ & - & - & 8 & 2 & $0.30 \pm 0.1$ & $0.87 \pm 0.1$ & $5.21 \pm 0.5$ \\
\hline
\end{tabular}



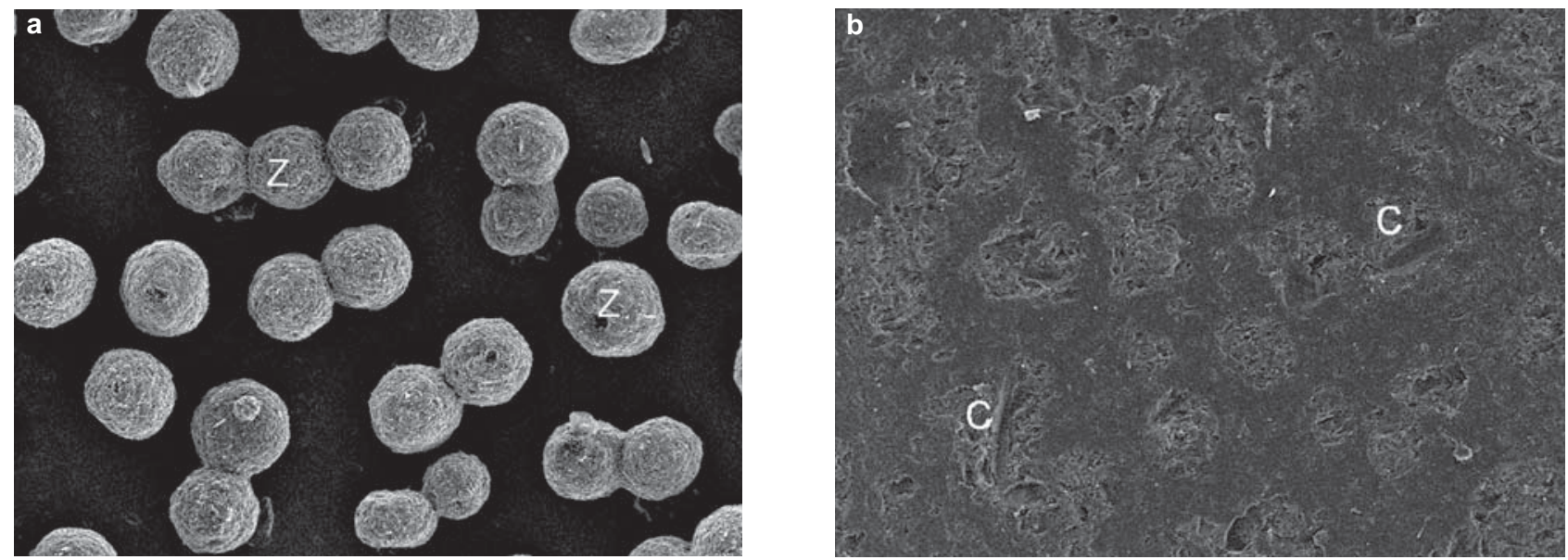

Figure 1- Scanning electron microscopy images in SE mode using 2,000x magnification showing: a) base of new bracket with zirconia pearls $(Z)$ as a mechanical retention mechanism spread on the alumina surface; b) base of bracket following tribochemical silica coating. Note the absence of zirconia pearls. Instead, the alumina surface presented cracks on the spots where the zirconia pearls were sputtered $(C)$

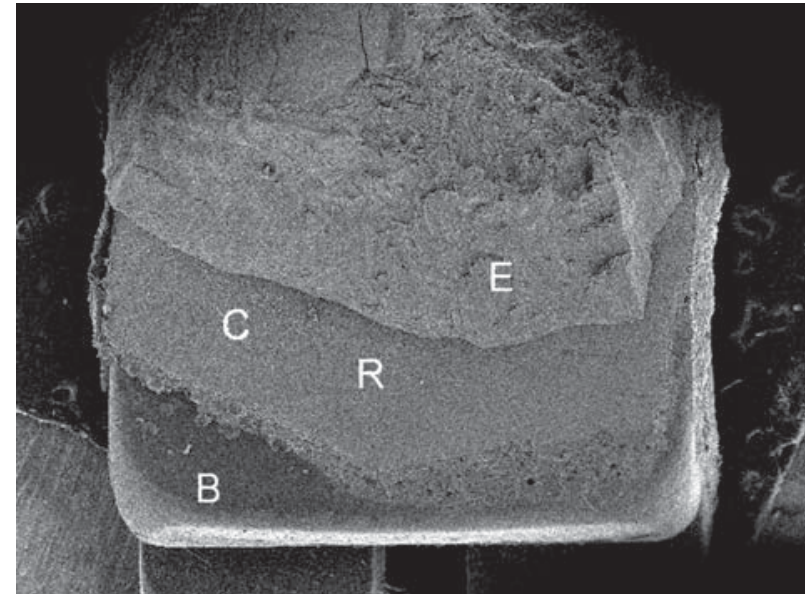

Figure 2- Scanning electron microscopy images in SE mode at 2,000x magnification showing brackets with mixed failure for Gh-TC with $>50 \%$ of resin composite on the bracket (adhesive remnant index - $A R I=1$ ) associated with enamel fracture. The bracket $(B)$, composite $(C)$, enamel $(E)$ and spot of roughness evaluated $(R)$ are showed on the micrograph

the adhesive remnant index (ARI) for each group are presented in Table 2.

Figure 1 shows the base of ceramic brackets with and without tribochemical silica coating. Two specimens for $\mathrm{Gc}$ and $\mathrm{Gt}$, three specimens for GcTC, Gt and Gt-TC showed damage to the enamel surface with eventual dentin fracture (3 specimens) (Figure 2). For Gt-TC, two brackets debonded during the thermocycling procedure. The bond strength values were recorded as $0 \mathrm{MPa}$ for these specimens.

\section{DISCUSSION}

Surface treatments for the "rebonding" procedure of ceramic brackets have been suggested in previous studies ${ }^{1,27}$. The aim of this research was to test the increase in bond strength and stability of the adhesive using a post-heat treatment on the silanized surface following tribochemical silica coating on monocrystalline alumina brackets that where submitted to different aging procedures. Data from the SBS tests verified that this strategy had an effect on bracket adhesion following aging. The hypotheses were accepted.

Shear bond strength is the most common test used to evaluate adhesion in orthodontics brackets $^{1,27}$. However, the literature shows that greater cohesive failure, rather than the nature of the stress, is responsible for bonding failure; moreover, it seems more appropriate to refer to the term "shear bond strength" as the loading mode ${ }^{3}$. Thus, the mechanics of this test associated with the large surface bonding area $\left(12.25 \mathrm{~mm}^{2}\right)$ could explain the rate of damage on the enamel surface (13 specimens) (Figure 2).

Regarding the sandblasted surfaces, alumina and silica-modified alumina particles play an important role in improving the bonding strength of resin to oxide ceramics, as shown by previous studies $^{8}$. This procedure is also used in orthodontic clinical practice to remove resin residue on the brackets permitting "rebonding". In addition, previous studies have verified that the use of silica-modified alumina particles to promote tribosilicatization of the brackets is preferable for promoting a chemical reaction between the silica and silane coupling agent ${ }^{1}$. Furthermore, the original adhesion mechanism (mechanical retention by zirconia pearls) was compromised, even when using a lower time (5 s) than other studies (15 s) to sandblast the surface (Figure 1).

Cattani Lorente, et al. $^{5}$ (2010) showed that the use of small-sized silica-modified alumina 
particles, such as Cojet, presented less damage on the ceramic surface than other frequently used particles. The SEM images suggest that greater bracket roughness was achieved following the protocol used to sandblast the surface concentrated on the zirconia pearl sites (Figure 1). Despite this fact, this procedure (Gt) showed results similar to other studies ${ }^{27}$, in that the bond strength was statistically lower, with a higher adhesive remnant index (ARI) than the control group (Gc) (Table 3). However, post-heat treatment (Gh) restored the bond strength values and ARI when the original adhesion mechanism was used on the new brackets (Table 1).

This effect was caused by the increase in siloxane links in the bonding agent and solvent evaporation in the mixture ${ }^{12,20}$. Solvent molecules trapped on the adhesive interface can influence the degradation process by accelerating hydrolysis ${ }^{13,19,20}$. This study applied post-heat treatment to a silanized surface and verified the influence of this approach on the shear bond strength and ARI in ceramic brackets (Table 2). Even so, the SBS results for Gc and GcTC showed a lower standard deviation than $\mathrm{Gh}$ and Gh-TC, respectively.

Numerous studies involving bracket adhesion have presented results using only thermocycled groups $1,6,10,27$. The present study also assessed the influence of storage on the shear bond strength results with and without thermocycling. The effect that water can have on polymeric materials is well established. Hydration can promote resin matrix plasticization, hydrolytic degradation of the resin matrix with additional interfacial degradation between the resin matrix and inorganic fillers, reducing strength and toughness ${ }^{24}$. Moreover, a rough surface has been documented following composite fracture ${ }^{21}$. The rough amplitude could provide an indication of material toughness when similar fracture modes and composite materials are compared. A general rule of thumb is that the fewer features on the surface, the lower the toughness ${ }^{11}$.

The statistically different results (Table 1 ) obtained for both roughness parameters (Ra and Rc) between the thermocycled and non-thermocycled groups, after a Gaussian filter was applied to remove the waviness of the surface, suggests that thermocycling has an effect on the mechanical properties of the resin composite. The lower surface roughness in the thermocycled groups indicates that less energy was required for cracks to grow at the resin/enamel interface than in non-thermocycled groups. However, 2-way ANOVA determined that the additional use of thermocycling under storage for 100 days had no statistical effect on the shear bond strength values or on the adhesive remnant index (Table 2), probably due to the test design (shear bond strength test) ${ }^{3}$.
Minimal risk of damage to the enamel surface during "debonding" and no adhesive remnant under the enamel surface are desirable features for a bracket system. The fact that the results were obtained using the shear bond strength test could be a limitation of this study regarding any clinical correlation with enamel damage.

\section{CONCLUSION}

Despite of the limitations of this study, it can be concluded that:

1) post-heat treatment of silanized surface following tribochemical silica coating improved shear bond strength for MAB;

2) using a resin composite, the association of thermocycling and storage did not produce any additional effect on the bond strength between the $M A B$ and enamel compared with storage alone in distilled water for the same period.

\section{REFERENCES}

1- Atsü S, Çstalbaş B, Gelgör IE. Effects of silica coating and silane surface conditioning on the bond strength of rebonded metal and ceramic brackets. J Appl Oral Sci. 2011;19:233-9.

2- Blatz MB, Chiche G, Holst S, Sadan A. Influence of surface treatment and simulated aging on bond strengths of luting agents to zirconia. Quintessence Int. 2007;38:745-53.

3- Braga RR, Meira JB, Boaro LC, Xavier TA. Adhesion to tooth structure: a critical review of "macro" test methods. Dent Mater. 2010;26:e38-49.

4- Carvalho RF, Martins ME, Queiroz JR, Leite FP, Özcan M. Influence of silane heat treatment on bond strength of resin cement to a feldspathic ceramic. Dent Mater J. 2011;30:392-7. 5- Cattani Lorente M, Scherrer SS, Richard J, Demellayer R, AmezDroz M, Wiskot HWA. Surface roughness and EDS characterization of a Y-TZP dental ceramic treated with the CoJet ${ }^{\text {TM }}$ Sand. Dent Mater. 2010;26:1035-42.

6- Chung $\mathrm{CH}$, Friedman DS, Mante FK. Shear bond strength of rebonded mechanically retentive ceramic brackets. Am J Orthod Dentofacial Orthop. 2002;122:282-7.

7- Corazza PH, Cavalcanti SC, Queiroz JR, Bottino MA, Valandro LF. Effect of post-silanization heat treatments of silanized feldspathic ceramic on adhesion to resin cement. J Adhes Dent. 2013; doi: 10.3290/j.jad.a29592.

8- Della Bona A, Donassollo TA, Demarco FF, Barrett AA, Mecholsky JJ Jr. Characterization and surface treatment effects on topography of a glass-infiltrated alumina/zirconia-reinforced ceramic. Dent Mater. 2007;23:769-75.

9- Fabianelli A, Pollington S, Papacchini F, Goracci C, Cantoro $A$, Ferrari $M$, et al. The effect of different surface treatments on bond strength between leucite reinforced feldspathic ceramic and composite resin. J Dent. 2010;38:39-43.

10- Grabouski JK, Staley RN, Jakobsen JR. The effect of microetching on the bond strength of metal brackets when bonded to previously bonded teeth: an in vitro study. Am J Orthod Dentofacial Orthop. 1998;114:452-60.

11- Greenhalgh ES. Failure analysis and fractography of polymer composites. Cambridge: Woodhead Publishing; 2009.

12- Hooshmand T, van Noort R, Keshvad A. Bond durability of the resin-bonded and silane treated ceramic surface. Dent Mater. 2002;18:179-88. 
13- Ishida $\mathrm{H}$, Koenig JL. Effect of hydrolysis and drying on the siloxane bonds of a silane coupling agent deposited on E-glass fibers. J Polym Sci: Part B Polym Phys. 1980;18:233-7.

14- Kern M, Barloi A, Yang B. Surface conditioning influences zirconia ceramic bonding. J Dent Res. 2009;88:817-22.

15- Lung CY, Matinlinna JP. Aspects of silane coupling agents and surface conditioning in dentistry: an overview. Dent Mater. 2012;28:467-77.

16- Matinlinna JP, Özcan M, Lassila LV, Vallittu PK. The effect of a 3-methacryloxypropyltrimethoxysilane and vinyltriisopropoxysilane blend and tris(3-trimethoxysilylpropyl)isocyanurate on the shear bond strength of composite resin to titanium metal. Dent Mater. 2004;20:804-13.

17- Monticelli F, Toledano M, Osorio R, Ferrari M. Effects of temperature on the silane coupling agents when bonding core resin to quartz fiber posts. Dent Mater. 2006;22:1024-8.

18- Özcan M, Matinlinna JP, Vallittu PK, Huysmans MC. Effect of drying time of 3-methacryloxypropyl-trimethoxysilane on the shear bond strength of a composite resin to silica-coated base/ noble alloys. Dent Mater. 2004;20:586-90.

19- Plueddemann EP. Silane coupling agents. New York: Plenum Press; 1991.

20- Queiroz JRC, Benetti P, Özcan M, Oliveira LFC, Della Bona A, Takahashi FE, et al. Surface characterization of feldspathic ceramic using ATR FT-IR and ellipsometry after various silanization protocols. Dent Mater. 2012;28:189-96.
21- Quinn JB, Quinn GD. Material properties and fractography of an indirect dental resin composite. Dent Mater. 2010;26:589-99. 22- Regan D, LeMasney B, Van Noort R. The tensile bond strength of new and rebonded stainless steel orthodontic brackets. Eur J Orthod. 1993;15:125-35.

23- Russel JS. Aesthetic orthodontic brackets. J Orthod. 2005;35:146-63.

24- Shah MB, Ferracane JL, Kruzi JJ. R-curve behavior and toughening mechanisms of resin-based dental composites: Effects of hydration and post-cure heat treatment. Dent Mater. 2009;25:760-70.

25- Shen C, Oh W, Williams JL. Effect of post-silanization drying on the bond strength of composite to ceramic. J Prosthet Dent. 2004;91:453-8.

26- Sonis AL. Air abrasion of failed bonded metal brackets: a study of shear bond strength and surface characteristics as determined by scanning electron microscopy. Am J Orthod Dentofacial Orthop. 1996;110:96-8.

27- Toroglu MS, Yaylali S. Effects of sandblasting and silica coating on the bond strength of rebonded mechanically retentive ceramic brackets. Am J Orthod Dentofacial Orthop. 2008;134:181.e1181.e7.

28- Wolfart M, Lehmann F, Wolfart S, Kern M. Durability of the resin bond strength to zirconia ceramic after using different surface conditioning methods. Dent Mater. 2007;23:45-50. 